\title{
Effect of car speed on amount of air supplied by ventilation system to the space of car cabin
}

\author{
Jan Fišer ${ }^{1, a}$ and Jan Pokorný ${ }^{1}$ \\ ${ }^{1}$ Faculty of Mechanical Engineering, Brno University of Technology, Technická 2, 61669 Brno, Czech Republic
}

\begin{abstract}
The amount of air supplied by ventilation system (HVAC system) of a car into a cabin is one of the main parameters for the correct simulation and prediction of a car cabin heat load. This amount is not based only on the current setting of the HVAC system, but also on the actual operating conditions and speed of the car. The authors therefore carried out experiments in the cabin of a passenger car in real traffic, while observing the amount of air on the speed of the car and setting of flap in mixing chamber. In a subsequent analysis the authors defined dependence of the airflow rate supplied by HVAC system on the speed of the car. Obtained empirical formulas were then used as a part of the code which calculates the data for the HVAC boundary conditions in the simulation of the car cabin environment.
\end{abstract}

\section{Introduction}

The team of Department of Thermodynamics and Environmental Engineering as other international teams is involved in projects which are focused on the design of models and methods for prediction of cabin environment, thermal load of car cabin and thermal comfort prediction $[1,2,3,4,5,6]$. In recent years, the team was mainly focused on the development of the model for prediction of thermal load of a cabin which is design to a quick prediction of the amount of energy required for heating, ventilation and air conditioning of the cabin. The basic requirements for the developed model, was its universal applicability to different geometries of the car cabins and the ability to integrate the data from real traffic measurements as an input boundary conditions. For this reason the special geometry generator module was designed and the input of this generator are forty-four typical geometrical parameters of the car body and the cabin. During the design and testing phase of the cabin heat load model the volumetric flow of the air distributed into the cabin and its dependency on car speed were identified as very significant parameters affecting the accuracy of prediction of cabin heat load.

\section{Methods}

To investigate the dependence of the amount of air supplied to the moving car the simplified method based on measuring the speed of air in front of air outlet was used. Also three fundamental assumptions were taken in to account:
- The amount of air which is sucked by the main fan from outside of the car is same as amount of air supplied in to the cabin.

- The speed of air in front of the central air outlet is correlated with the car speed.

- The distribution ratio of air between distribution outlets is constant and not depends on the car speed.

Based on previous assumptions the next procedure of experiment was followed:

- The amount of air sucked into the HVAC system from outside environment was measured. The car was parked in the garage and ambient air speed was close to zero.

- The air speed in front of selected air outlet in the cabin was measured. The car was parked in the garage and measured speed of air was then set as basic speed which is equal to the zero speed of the test car.

- The air speed in front of selected air outlet and speed of the car were measured during real driving conditions.

- The data was post processed to find a correlation between car speed and speed of air in front of selected air outlet.

- Definition of empirical formulas for calculation of amount of air based on car speed and setting of HVAC system.

\footnotetext{
${ }^{\mathrm{a}}$ Corresponding author: fiser@fme.vutbr.cz
} 
The supply air flow rate was calculated based on the equation 1 , where the area $S$ is a free area of suction fan opening and $w$ is average speed of the air.

$$
\dot{V}=S \cdot w
$$

\subsection{Equipment for experiment}

The hot wire anemometer (Testo $435+$ Anemometric probe 06351535 ) was placed in the axis and at the distance of $5 \mathrm{~cm}$ in front of the outlet grille of central dashboard outlet. The shut-off flap of the outlet was set as fully open. The air distribution system of the test vehicle (Škoda Felicia Combi) was set to supply air from the central dashboard outlets and through the outlet under the windshield. The air speed in front of the central outlet was measured continuously during whole driving test and the data was logged into TESTO 435 logger.

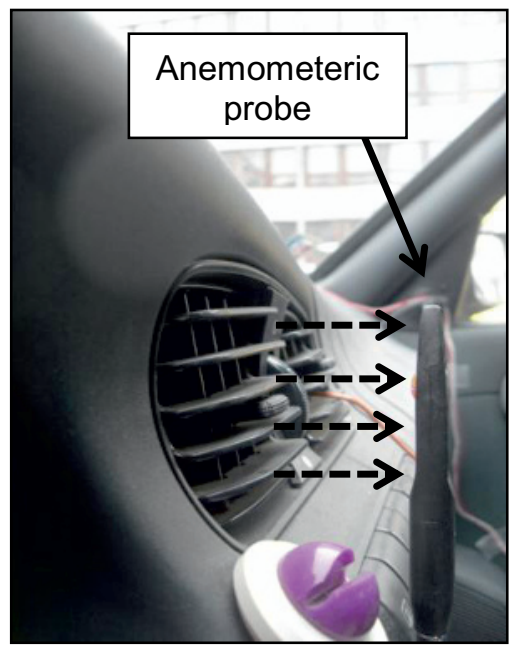

Figure 1. Position of anemometric probe in front of central dashboard outlet.

Before the start of the test driving the volumetric flow of air sucked into the HVAC system was measured in garage and the procedure base on measurement of air speed in mesh of two by six points was used as can be seen in Figure 2. This amount of air was set as basic for zero speed of the car and the vales are listed in Table 1.

Table 1. Measured volumetric flow and air speed for zero car speed.

\begin{tabular}{|c|c|c|}
\hline Fan speed & $\begin{array}{c}\text { Volumetric flow sucked } \\
\text { in to the fan } \\
{[\mathbf{l} / \mathbf{s}]}\end{array}$ & $\begin{array}{c}\text { Air speed in } \\
\text { front of outlet } \\
\text { [m/s] }\end{array}$ \\
\hline 2 & 21.7 & 2.63 \\
\hline 4 & 48.6 & 5.88 \\
\hline
\end{tabular}

The position of the test car was measured using Global Positioning System and common smartphone Nokia 6220 with special freeware Nokia Sports tracker. The software logged position of car each $0.1 \mathrm{~s}$ and from two different positions is able to calculate bearing and speed of the car. The data from hot wire anemometer,
TESTO logger and GPS were synchronised based on logging time stamp of the samples.

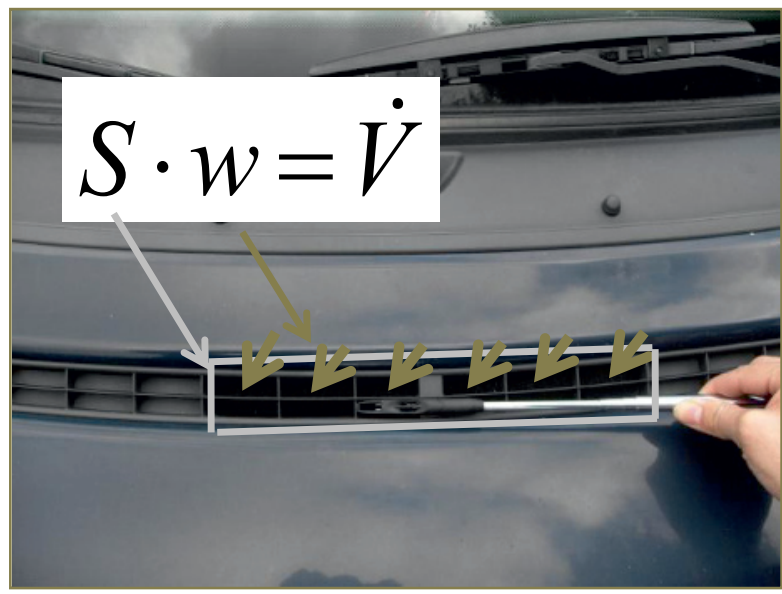

Figure 2. Measurement of volumetric flow on the inlet of the fan.

\section{Description of the driving experiment}

The measurement was realized in real traffic condition thus the setup modes of HVAC system was based on demands of car crew (authors of the paper). All modes which were used during test cycle are listed in Table 1. and showed in figure 3 .

Table 2. Measured modes of HVAC system.

\begin{tabular}{|c|c|c|c|}
\hline Time & Description & $\begin{array}{c}\text { Fan } \\
\text { speed }\end{array}$ & $\begin{array}{c}\text { Mix flap } \\
\text { position }\end{array}$ \\
\hline $11: 13$ & Start of test driving to Vyškov & 2 & $1 / 4$ \\
\hline $11: 29$ & Increase of heating & 2 & $1 / 2$ \\
\hline $11: 59$ & Stop in Vyškov & 0 & $1 / 2$ \\
\hline $12: 06$ & Start of test driving to Brno & 4 & $1 / 4$ \\
\hline $12: 18$ & Decreasing of heating & 2 & $1 / 2$ \\
\hline $12: 59$ & End of driving test & - & - \\
\hline
\end{tabular}

The test circuit was track Brno-Vyškov and back with total length of $86 \mathrm{~km}$, with time of 106 minutes. The test driving started at Brno 11:13 with fan speed controller set to second step and mixing flap of heating set to $1 / 4$ (one quarter) of full heating mode. After sixteen minutes at $11: 29$, the heating was found as insufficient and the position of mixing flap was change to $1 / 2$ (one half) of full heating mode. At 11:59 the test car reached Vyškov where was stopped until 12:06. Back driving to Brno started with fan speed controller set to highest fourth step and mixing flap was set to one quarter of full heating. This mode was select to prevent the fogging of the windshield. After 12 minutes the HVAC system was turn back to typical steady mode: fan speed second step, the position of mixing flap to $1 / 2$ (one half) of full heating mode. 


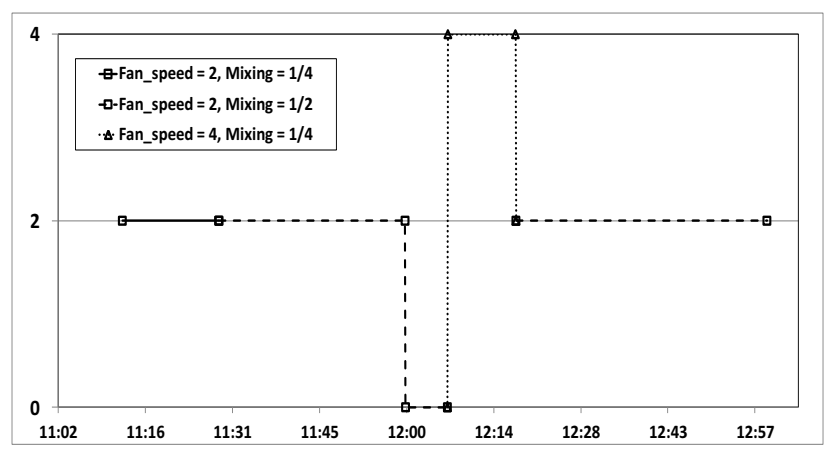

Figure 3. The modes of the HVAC system used during test driving.

\section{Discussion of results}

The data for car speed, speed of air in front of measured outlet and air temperature are depicted in Figure 4., 5. and 6. Car speed during test driving was in range from $0 \mathrm{~km} / \mathrm{h}$ up to speed limit $90 \mathrm{~km} / \mathrm{h}$. The first part of driving (till 11:27) took place in the city, thus the maximal car speed was about $60 \mathrm{~km} / \mathrm{h}$, average speed was even lower due to the stops at traffic lights (see zero car speed). Outside the city the driver used A-road from Brno to Vyškov and average speed increase at value between 60 and $90 \mathrm{~km} / \mathrm{h}$.

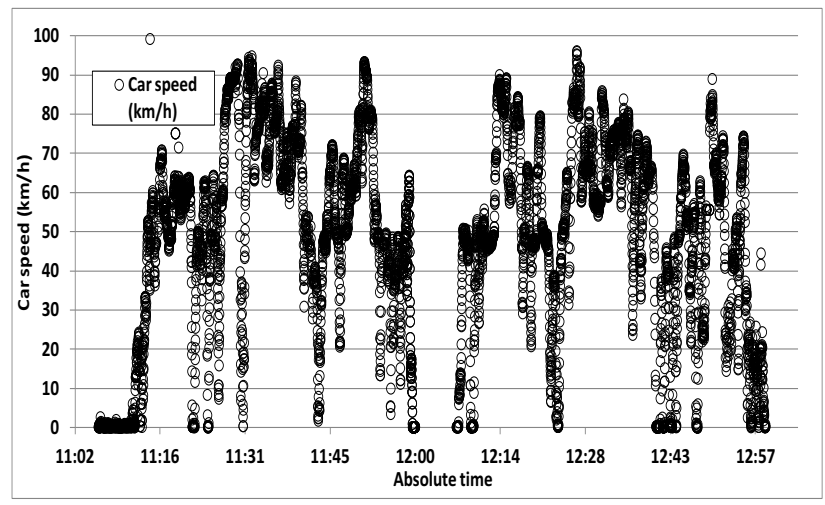

Figure 4. The car speed during test drive circuit.

The air speed in front of middle outlet is shown in Figure 5. As can be seen the value of air speed is mainly influenced by setting of fan controller and also by speed of the car.

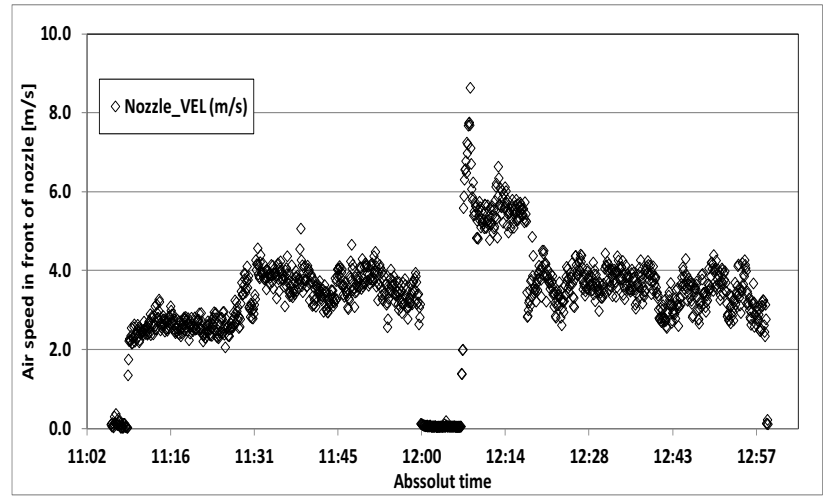

Figure 5. The air speed in front of the central dashboard outlet.
For example in 11:27 the test car left Brno and speed increased up to $90 \mathrm{~km} / \mathrm{h}$, the outside convection and heat loss of cabin also increased what was identified by driver as decrease of thermal comfort. So that at 11:29 the position of mixing flap was changed from $1 / 4$ to $1 / 2$ and air speed was increased from average $2.2 \mathrm{~m} / \mathrm{s}$ to $3.5 \mathrm{~m} / \mathrm{s}$. After correction the temperature of supplied air increased from average $25^{\circ} \mathrm{C}$ to $35^{\circ} \mathrm{C}$ as can be seen in figure 6 .

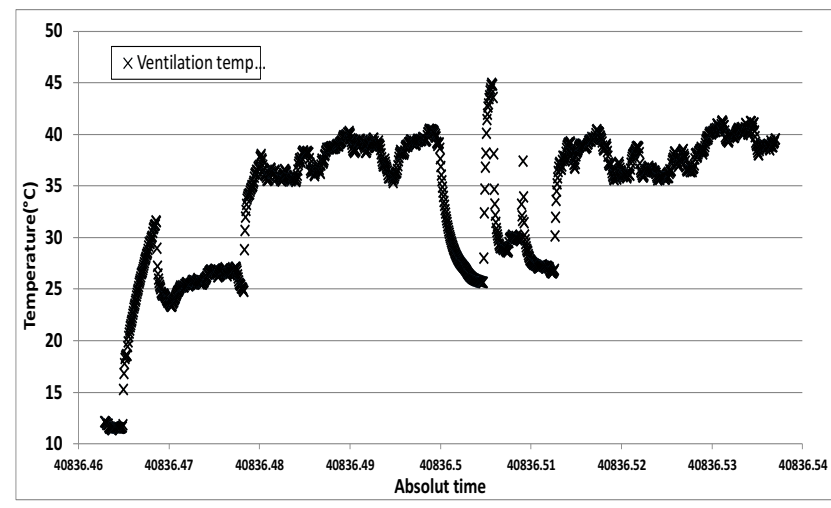

Figure 6. The temperature of air in front of the central dashboard outlet.

During the test driving three different modes of HVAC system were used. Based on these combinations the air speed data and car speed data were sorted to the three groups and in next step the data were plotted to the graph of air speed versus car speed. The result is shown in Figure 7. The most of data belongs to combination Fan speed 2 , mixing flap $1 / 2$, because this setting was optimal for keeping the cabin temperature close to crew thermal comfort. Other two combinations were used in shorter period thus the amount of points is lower but still sufficient for correct regression.

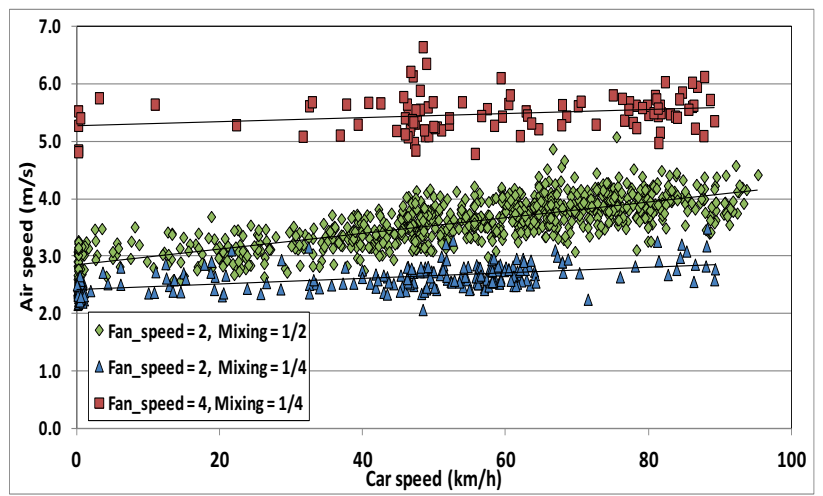

Figure 7. Air speed in front of the central outlet vs. speed of the test car.

The final linear functions which approximate data from measurements are in Table 3. Last column of table shows the ratio of functions values when the car speed is equal to $90 \mathrm{~km} / \mathrm{h}$ and $0 \mathrm{~km} / \mathrm{h}$. As can be seen the highest dependency of air speed on car speed was observed in combination: Fan speed $2+$ Mixing 1/2. 
Table 3. Regression functions for Figure 7. and air speed growth ratio.

\begin{tabular}{|c|c|c|}
\hline HVAC setting & Approximation function & $\begin{array}{c}\text { Speed } \\
\text { growth } \\
\text { ratio }\end{array}$ \\
\hline FAN 2 + Mixing 1/4 & $\boldsymbol{y}=0.0049 x+2.41$ & 1.183 \\
\hline FAN 2+ Mixing 1/2 & $y=0.0137 x+2.85$ & 1.432 \\
\hline FAN 4 + Mixing 1/4 & $y=0.0036 x+5.27$ & 1.061 \\
\hline
\end{tabular}

The values of volumetric flows for each setting of HVAC system and for car speed $0 \mathrm{~km} / \mathrm{h}$ and $90 \mathrm{~km} / \mathrm{h}$ are in Table 4. The highest increase of flow is reached in combination Fan speed $2+$ Mixing 1/2. The volumetric flow increase from $21.7 \mathrm{l} / \mathrm{s}$ for car speed $0 \mathrm{~km} / \mathrm{h}$ up to $31.1 \mathrm{l} / \mathrm{s}$ for car speed $90 \mathrm{~km} / \mathrm{h}$ which is increase of 43.2 $\%$. On the other hand lowest impact was observed for the combination of Fan speed $4+$ Mixing 1/4. The volumetric flow increase from $48.6 \mathrm{l} / \mathrm{s}$ for car speed $0 \mathrm{~km} / \mathrm{h}$ up to $51.6 \mathrm{l} / \mathrm{s}$ for car speed $90 \mathrm{~km} / \mathrm{h}$ which is increase of $6.1 \%$ only.

Table 4. Volumetric flow of air for various setting of HVAC system.

\begin{tabular}{|c|c|c|c|}
\hline HVAC set & $\begin{array}{c}\text { Car speed } \\
\mathbf{0 ~} \mathbf{~ k m} / \mathbf{h}\end{array}$ & $\begin{array}{c}\text { Car speed } \\
\mathbf{9 0} \mathbf{~ k m} / \mathbf{h}\end{array}$ & $\begin{array}{c}\text { Difference } \\
(\%)\end{array}$ \\
\hline FAN 2 + Mixing 1/4 & 20.8 & 24.6 & 18.3 \\
\hline FAN 2 + Mixing 1/2 & 21.7 & 31.1 & 43.2 \\
\hline FAN 4 + Mixing 1/4 & 48.6 & 51.6 & 6.1 \\
\hline
\end{tabular}

\section{Conclusions}

The data measured during test driving shows that the supply air flow rate is strongly dependent on the speed of the car when the fan speed is set at the second level in combination with the position of heating mixing flap on $1 / 2$ of full open. In such case, the increase of the volume flow is from $21.7 \mathrm{l} / \mathrm{s}$ at $0 \mathrm{~km} / \mathrm{h}$ to $31.1 \mathrm{l} / \mathrm{s}$ at car speed of $90 \mathrm{~km} / \mathrm{h}$ which is equal to the total increase of $43.2 \%$. In case of higher fan speed or a lower mixing ration of heating, increase of supply air is lower: $18.3 \%$ for the combination of the Fan speed $2+$ mixing flap in position $1 / 2$, and $6.1 \%$ for the combination of Fan speed $4+$ mixing flap of heating in position $1 / 4$.

Regression functions derived from the data statistic were integrated into the Cabin heat load model. This application increased accuracy of the input data for boundary condition which represents air supply of car HVAC system.

The model of Cabin heat load is still under development and next step will be validation and calibration of the model for Škoda Octavia $3^{\text {rd }}$ generation. It will be very interesting to repeat this measurement with car which is equipped with very sophisticated Climatronic air-conditioning system with digital regulation of fan speed.

\section{Acknowledgement}

Authors gratefully acknowledge the support from projects Netme centre - CZ.1.05/2.1.00/01.0002 and Excellence I - CZ.1.07/2.3.00/30.0005 of the Brno University of Technology.

\section{References}

1. J. Pokorný, J. Fišer, M. Jícha, Experimental Fluid Mechanics 2011, (TUL, Liberec, 2011).

2. J. Fišer, J. Pokorný, D. Podola, M. Jícha, 31. Setkání kateder mechaniky tekutin a termomechaniky, (VUT v Brně, Brno, 2012).

3. J. Pokorný, J. Fišer, M. Jícha, The international journal of ventilation 11/4, 393-406 (2013).

4. A. Fujita, J. Kanemaru, H. Nakagawa, Y. Ozeki, JSAE Review 22 , 39-47, (2001).

5. P. Rugh, L. Chaney, J. Lustbader, SAE World Congress 2007, (SAE, Detroit, Michigan, 2007).

6. C. Wachsmuth, Precooling Strategies for Passengers Vehicles, PhD thesis (Nelson Mandela Metropolitan University, 2009). 